\title{
Uterine Involution
}

National Cancer Institute

\section{Source}

National Cancer Institute. Uterine Involution. NCI Thesaurus. Code C92909.

Atrophy or reduction of the size of the uterine corpus. 